\title{
Comparison of different criteria for the definition of insulin resistance and its relationship to metabolic risk in children and adolescents
}

\author{
Seon Hwa Lee, MD, \\ Moon Bae Ahn, MD, \\ Yu Jung Choi, MD, \\ Seul Ki Kim, MD, \\ Shin Hee Kim, MD, \\ Won Kyoung Cho, MD, PhD, \\ Kyoung Soon Cho, MD, \\ Byung-Kyu Suh, MD, PhD, \\ Min Ho Jung, MD, PhD
}

Department of Pediatrics, College of Medicine, The Catholic University of Korea, Seoul, Korea
Received: 23 December, 2019

Revised: 26 March, 2020

Accepted: 3 April, 2020

Address for correspondence:

Min Ho Jung, MD

Department of Pediatrics, Yeouido St. Mary's Hospital, College of Medicine, The Catholic University of Korea, 1063(yuksam)-ro, Yeongdeungpogu, Seoul 07345, Korea

Tel: +82-2-3779-1131

Fax: +82-2-783-2589

E-mail:jmhpe@catholic.ac.kr

https://orcid.org/0000-0001-51887041
Purpose: Childhood obesity frequently persists into adulthood and is associated with insulin resistance (IR) and increased long-term morbidity and mortality. We compared IR criteria concerning 'age-specific cutoff point' (ACOP) and 'fixed cutoff point' (FCOP) for the identification of IR and investigated their correlation with metabolic syndrome (MS).

Methods: Data were acquired from the 5th Korea National Health and Nutrition Examination Survey (2010-2011). Participants ranged from 10 to 17 years of age and underwent fasting plasma glucose, insulin concentration, and lipid panel measurements. High fasting plasma insulin levels or increased homeostatic model assessment insulin resistance (HOMA-IR) were defined as IR. We analyzed MS and IR frequencies according to FCOP or ACOP.

Results: Among 719 participants, 165 (22.9\%) were overweight or obese based on their body mass index. We found no prevalence of MS in underweight/normal weight participants and $12.7 \%$ prevalence rate in overweight or obese participants. IR according to ACOP was more closely associated with MS than IR according to FCOP. No differences were found in predicting the frequency of MS using FCOP or ACOP in both fasting plasma insulin and HOMA-IR.

Conclusion: The frequency of MS in participants with IR defined using ACOP and FCOP was similar. However, IR using ACOP was more closely associated with MS than IR using FCOP.

Keywords: Obesity, Insulin resistance, Metabolic syndrome, Child, Adolescents

\section{Introduction}

Rising prevalence rates of overweight and obesity in numerous countries have been described as a global pandemic. ${ }^{1,2)}$ High rates of childhood obesity lead to associated health consequences ranging from psychosocial consequences to adverse metabolic effects on blood pressure (BP), total cholesterol (TC), triglyceride (TG) concentrations, and insulin resistance (IR). ${ }^{3)}$ IR and glucose intolerance are frequent in children and adolescents with obesity and lead to a significant risk of hypertension and cardiovascular disease (CVD), early atherosclerosis, progressive obesity, acanthosis nigricans, dyslipidemia, fatty liver, polycystic ovarian syndrome (PCOS), and type 2 diabetes (T2DM). ${ }^{4}$ IR is also considered a trigger factor in metabolic syndrome (MS) that leads to morbidity and mortality. ${ }^{2,5-9)}$

Early detection of IR is important to prevent these associated health consequences. There is a lack of clarity as to how IR in childhood is best assessed, in what clinical disorders it occurs, and whether it can be treated or prevented. ${ }^{4,10)}$ The gold standard for assessing IR in humans is the hyperinsulinemic-euglycemic clamp assessment. ${ }^{11)}$ However, the hyperinsulinemiceuglycemic clamp is not applicable in the clinical setting as it is an invasive procedure and 
technically complex, especially for use in the pediatric age group, ${ }^{2)}$ and it can only be used for research purposes. ${ }^{4)}$ Therefore, methods such as fasting plasma insulin level, fasting plasma glucose (FPG) to insulin ratio (FGIR), homeostatic model assessment IR (HOMA-IR), and the quantitative insulin-sensitivity check index (QUICKI) are frequently used for population screening. ${ }^{2,4)}$ HOMA-IR has been found to be considerably more reliable than FGIR and QUICKI for quantifying the degree of IR in children with obesity. ${ }^{4,12)}$ In addition, FPG variations in the pediatric population are rarely significant; therefore, some authors propose that fasting plasma insulin alone can be used to diagnose IR in children., ${ }^{2,13,14}$ Moreover, there is no strict definition for IR in children or adolescents.

Puberty is associated with a temporary increase in IR; however, the cause is not fully understood. IR is more closely related with age than with pubertal stage; thus, it is possible that specific fasting plasma insulin and HOMA-IR values by age group and sex may be applicable. ${ }^{2,15,16)}$ Despite an acceptable HOMA-IR cutoff limit for IR of 2.5 in adults, corresponding values for IR in prepubertal and pubertal children and adolescents are scare. ${ }^{4,17)}$ Here, we classify the value of fasting plasma insulin and HOMA-IR by age group and re-name it 'age-specific cutoff point' (ACOP). Moreover, 'fixed cutoff point' (FCOP) refers to the most used cutoff point described in the literature for fasting plasma insulin and for HOMA-IR., ${ }^{2,12,18,19)}$

Our study aimed to compare measures of IR using ACOP and FCOP in fasting plasma insulin and HOMA-IR for diagnosing IR as a predictor of MS prevalence.

\section{Materials and methods}

\section{Data collection}

Data were obtained from the 5th Korea National Health and Nutrition Examination Survey (KNHANES V, 20102011). KNHANES $V$ was a cross-sectional and nationally representative survey based on a stratified sampling design conducted by the Korean Ministry of Health and Welfare. A total of 11,230 individuals from 10 to 17 years of age were included in the KNHANES V. After providing informed consent, participants and their parents were interviewed at home and the participants underwent various examinations including blood tests. Weight was measured with a medical balance (GL-6000-20, CASKOREA, Seoul, Korea) and height was measured to the nearest $0.1 \mathrm{~cm}$ using a wall-mounted stadiometer (SECA 220, SECA, Hamburg, Germany). Body mass index (BMI) was calculated by dividing the weight $(\mathrm{kg})$ by the square of the height $\left(\mathrm{m}^{2}\right)$. Waist circumference (WC) was measured to the nearest $0.1 \mathrm{~cm}$ at the narrowest point between the lower end of the last rib and the upper rim of the right iliac crest. BP was measured after participants were asked to rest in a sitting position for 5 minutes. The systolic and diastolic BP was recorded three times, and the mean value was used for analysis.
Blood samples were transported daily to the Central Laboratory (NEODIN Medical Institute, Seoul, Korea). FPG, TG, and high-density lipoprotein cholesterol (HDL-C) concentrations were measured according to standard procedures using a Hitachi Automatic Analyzer 7600 (Hitachi, Tokyo, Japan). Body composition was measured using a standardized method involving dual energy $\mathrm{x}$-ray absorptiometry (DEXA; DISCOVERY-W fan-beam densitometer Hologic Inc., Bedford, MA, USA). Insulin concentration was measured with a radioimmunoassay kit (1470 WIZARD gamma-counter PerkinElmer, Turku, Finland). Insulin sensitivity was evaluated according to HOMA-IR, which was calculated using the following equation: HOMA-IR=fasting plasma insulin $(\mu \mathrm{U} / \mathrm{mL}) \times \mathrm{FPG}(\mathrm{mg} / \mathrm{dL}) / 405 .{ }^{17)}$

\section{Study design}

Of 11,230 participants, a subsample $(\mathrm{n}=1,252)$ aged 10-17 years underwent FPG, insulin level, and lipid panel measurements. Participants for whom data were missing were excluded $(n=494)$. Participants with chronic systemic diseases such as T2DM, thyroid disease, rheumatoid arthritis, cancer, $C V D$, and other disabled status were excluded $(n=30)$. Nine participants who had not fasted for at least 8 hours prior to testing were also excluded. Thus, a total of 719 participants (389 males, 330 females) were assessed. Participants were classified as underweight/normal weight (UN group) if their BMI was lower than the 85th percentile, and overweight/obese (OB group) if their BMI was higher than or equal to the 85 th percentile, based on the 2017 Korean National Growth Charts. ${ }^{20)}$

Hyperinsulinemia, used as a diagnostic marker of IR, was identified when the fasting plasma insulin value was above the cutoff point according to $(\mathrm{A})$ or $(\mathrm{B})$ :

(A) $15 \mu \mathrm{U} / \mathrm{mL}, \mathrm{FCOP}^{19)}$

(B) ACOP by sex ( $>95$ th percentile of fasting plasma insulin, as reported in a previous study $\left.{ }^{5}\right)$, as follows:

- $10-11$ years: $16.0 \mu \mathrm{U} / \mathrm{mL}$ (male), $18.3 \mu \mathrm{U} / \mathrm{mL}$ (female)

- 11-12 years: $20.1 \mu \mathrm{U} / \mathrm{mL}$ (male), $21.7 \mu \mathrm{U} / \mathrm{mL}$ (female)

- 12-13 years: $21.0 \mu \mathrm{U} / \mathrm{mL}$ (male), $24.8 \mu \mathrm{U} / \mathrm{mL}$ (female)

- 13-14 years: $20.4 \mu \mathrm{U} / \mathrm{mL}$ (male), $23.7 \mu \mathrm{U} / \mathrm{mL}$ (female)

- 14-15years: $21.7 \mu \mathrm{U} / \mathrm{mL}$ (male), $18.2 \mu \mathrm{U} / \mathrm{mL}$ (female)

- 15-16 years: $20.2 \mu \mathrm{U} / \mathrm{mL}$ (male), $18.8 \mu \mathrm{U} / \mathrm{mL}$ (female)

• 16-17 years: $18.5 \mu \mathrm{U} / \mathrm{mL}$ (male), $19.8 \mu \mathrm{U} / \mathrm{mL}$ (female)

HOMA-IR was the other indicator of IR, which was considered when the value was above the following cutoff points:

(A) $3.16, \mathrm{FCOP}^{12)}$

(B) ACOP by sex ( $>95$ th percentile, as reported in a previous study ${ }^{5)}$ ), as follows:

- $10-11$ years: 3.70 (male), 4.10 (female)

- 11-12 years: 4.40 (male), 4.87 (female)

- 12-13 years: 4.52 (male), 5.65 (female)

- 13-14 years: 4.58 (male), 5.45 (female)

- 14-15 years: 5.01 (male), 4.15 (female)

- 15-16 years: 4.50 (male), 4.09 (female) 
-16-17 years: 4.08 (male), 4.50 (female)

We used the International Diabetes Federation (IDF) MS definition for participants aged $>10$ years. ${ }^{21)}$ Central obesity was defined as a $\mathrm{WC} \geq 90$ th percentile for age and sex except in females aged $\geq 16$ years $(\mathrm{WC} \geq 80 \mathrm{~cm}$ ) and in males aged $\geq 16$ years $(\mathrm{WC} \geq 90 \mathrm{~cm}){ }^{20)}$ MS was diagnosed when two or more of the following clinical features were detected: fasting TG level $\geq 130 \mathrm{mg} / \mathrm{dL},{ }^{22,23)}$ FPG concentration $\geq 100 \mathrm{mg} / \mathrm{dL}$ (5.5 mmol/ $\mathrm{L})$, systolic $\mathrm{BP} \geq 90$ th percentile or diastolic $\mathrm{BP} \geq 90$ th percentile, and HDL-C $<40 \mathrm{mg} / \mathrm{dL}$ for both sexes, except in females aged $\geq 16$ years (HDL-C concentrations $<50 \mathrm{mg} / \mathrm{dL}$ ). ${ }^{21}$ )

\section{Statistical analysis}

Data are expressed as mean \pm standard deviation or as numbers and percentages based on the characteristics of the variables. We used logistic regression analysis considering sex stratification to determine the association between IR and MS. The association between MS and obesity-related factors was subjected to logistic regression analysis. To compare the differences in performance (FCOP, ACOP), the areas under the curves (AUCs) were calculated using the DeLong method. A comparison of dyslipidemia frequencies between FCOP and ACOP was analyzed using a chi-square test. All statistical analyses were performed using SAS 9.4 (SAS Institute, Cary, NC, USA) and a P-value below 0.05 was considered statistically significant.

\section{Results}

\section{Characteristics of the study participants aged 10-17 years}

Among the 719 participants, 165 (22.9\%) were overweight or obese based on their BMI (Table 1). In the OB group, the mean values of weight, weight $z$-score, BMI $z$-score, fasting plasma insulin, WC, systolic BP, FPG levels, lipid panel, fat mass (FM), fat mass index (FMI), and HOMA-IR were significantly higher relative to participants in the UN group.

\section{The prevalence of MS}

The prevalence of MS among the participants was 2.9\% $(\mathrm{n}=21)$ with no prevalence of MS in the UN group, and $12.7 \%$ prevalence in the $\mathrm{OB}$ group. Among the $\mathrm{OB}$ group, males had a higher prevalence of MS (7.2\%) than females (5.5\%).

Table 1. Baseline characteristics of participants in the KNHANES V (2010-2011)

\begin{tabular}{|c|c|c|c|}
\hline Characteristic & $\begin{array}{l}\text { UN group } \\
(n=554)\end{array}$ & $\begin{array}{l}\text { OB group } \\
(n=165)\end{array}$ & $P$-value \\
\hline Age (yr) & $13.92 \pm 0.13$ & $13.26 \pm 0.27$ & 0.018 \\
\hline Male sex (\%) & $287(52.5)$ & $102(62.2)$ & 0.141 \\
\hline Weight (kg) & $50.14 \pm 0.56$ & $66.19 \pm 1.32$ & $<0.001$ \\
\hline Weight z-score & $0.20 \pm 0.05$ & $1.83 \pm 0.05$ & $<0.001$ \\
\hline BMI z-score & $-0.21 \pm 0.05$ & $1.58 \pm 0.05$ & $<0.001$ \\
\hline $\mathrm{FPG}(\mathrm{mg} / \mathrm{dL})$ & $88.56 \pm 0.36$ & $91.28 \pm 0.74$ & 0.001 \\
\hline Total cholesterol (mg/dL) & $155.73 \pm 1.43$ & $161.88 \pm 2.67$ & 0.036 \\
\hline Triglyceride (mg/dL) & $78.81 \pm 2.45$ & $112.34 \pm 8.14$ & $<0.001$ \\
\hline $\mathrm{LDL}-\mathrm{C}(\mathrm{mg} / \mathrm{dL})$ & $91.64 \pm 1.41$ & $104.43 \pm 3.53$ & 0.001 \\
\hline $\mathrm{HDL}-\mathrm{C}(\mathrm{mg} / \mathrm{dL})$ & $50.43 \pm 0.51$ & $44.86 \pm 0.95$ & $<0.001$ \\
\hline $\begin{array}{l}\text { Fasting plasma insulin } \\
(\mu \mid \cup / m L)\end{array}$ & $12.28 \pm 0.26$ & $18.71 \pm 0.87$ & $<0.001$ \\
\hline HOMA-IR & $2.70 \pm 0.06$ & $4.26 \pm 0.21$ & $<0.001$ \\
\hline Fat mass (kg) & $11.62 \pm 0.33$ & $22.26 \pm 0.66$ & $<0.001$ \\
\hline Percent body fat (\%) & $25.87 \pm 0.67$ & $36.75 \pm 0.68$ & $<0.001$ \\
\hline Trunk fat mass (kg) & $5.06 \pm 0.16$ & $10.88 \pm 0.38$ & $<0.001$ \\
\hline Trunk fat mass (\%) & $22.71 \pm 0.62$ & $35.61 \pm 0.68$ & $<0.001$ \\
\hline FMI $\left(\mathrm{kg} / \mathrm{m}^{2}\right)$ & $4.52 \pm 0.13$ & $8.58 \pm 0.24$ & $<0.001$ \\
\hline FFMI $\left(\mathrm{kg} / \mathrm{m}^{2}\right)$ & $14.66 \pm 0.11$ & $16.74 \pm 0.19$ & $<0.001$ \\
\hline Metabolic syndrome (\%) & $0(0)$ & $21(13.1)$ & $<0.001$ \\
\hline Central obesity (\%) & $3(0.3)$ & $76(47.6)$ & $<0.001$ \\
\hline Impaired fasting glucose (\%) & $20(3.6)$ & $14(11.2)$ & $<0.001$ \\
\hline Hypertension (\%) & $10(2.3)$ & $15(8.6)$ & 0.006 \\
\hline Hypertriglyceridemia (\%) & $49(9.1)$ & $52(30.5)$ & $<0.001$ \\
\hline Low HDL-C (\%) & $73(14.3)$ & $58(38.6)$ & $<0.001$ \\
\hline
\end{tabular}

Values are presented as mean \pm standard deviation or number (\%). KNHANES V, 5th Korea National Health and Nutrition Examination Survey (2010-2011): UN group, underweight/normal weight; OB group, overweight/obese; BMI, body mass index; FPG, fasting plasma glucose; LDL-C, low-density lipoprotein cholesterol; HDL-C, high-density lipoprotein cholesterol; HOMA-IR, homeostasis model assessment for insulin resistance; FMI, fat mass index; FFMl, fat free mass index.

Table 2. The incidence of insulin resistance using criteria stratified according to body mass index and sex

\begin{tabular}{|c|c|c|c|c|c|}
\hline Variable & UN group $(n=554)$ & OB group $(n=165)$ & Male $(n=389)$ & Female $(n=330)$ & Total $(n=719)$ \\
\hline \multicolumn{6}{|l|}{ Insulin } \\
\hline FCOP & $109(20.0)$ & $105(58.5)$ & $104(27.4)$ & $110(30.4)$ & $214(28.8)$ \\
\hline ACOP & $33(5.7)$ & 68 (35.9) & $53(13.2)$ & 48 (11.8) & $101(12.6)$ \\
\hline \multicolumn{6}{|c|}{ HOMA-IR } \\
\hline FCOP & $139(24.4)$ & $114(63.7)$ & $124(31.1)$ & $129(36.1)$ & $253(33.4)$ \\
\hline ACOP & $34(5.6)$ & $68(35.9)$ & $57(13.9)$ & 45 (10.9) & $102(12.5)$ \\
\hline
\end{tabular}

Values are presented as number (\%).

UN group, underweight/normal weight; OB group, overweight/obese; BMI, body mass index; FCOP, fixed cutoff points; ACOP, age-specific cutoff points; HOMA-IR, homeostasis model assessment for insulin resistance. 
Contributing factors for MS such as central obesity, impaired fasting glucose, hypertension, hypertriglyceridemia, and low HDL-C concentrations were observed in $47.6 \%, 11.2 \%, 8.6 \%$, $30.5 \%$, and $38.6 \%$ of the OB group, respectively. The prevalence rates for IR in the $\mathrm{OB}$ group, using fasting plasma insulin and HOMA-IR with ACOP, were $35.9 \%$ and $35.9 \%$, respectively. Using fasting plasma insulin and HOMA-IR with FCOP, the prevalence rates for IR were $58.5 \%$ and $63.7 \%$, respectively (Table 2).

Using fasting plasma insulin or HOMA-IR according to ACOP as compared to FCOP, there was concordance in 101 (43.7\%) and 102 participants (37.5\%), respectively, and no discrepancy for the diagnosis of IR. However, ACOP was consonant with FCOP in 505 (100\%) and 466 participants (100\%) for fasting plasma insulin and HOMA-IR, respectively, for a diagnosis of the absence of IR. Moreover, there was discrepancy in $113(56.3 \%)$ and 151 cases $(62.5 \%)$, respectively (Table 3). The frequencies (\%) of dyslipidemia of participants with IR according to fasting plasma insulin and HOMA-IR were significantly different in TG levels (Table 4).

\section{A comparison of ACOP and FCOP}

In logistic regression models, a significant association between MS and fixed or age-specific model of IR (FCOP or ACOP) using fasting plasma insulin levels was observed (odds ratio $[\mathrm{OR}], 8.62 ; 95 \%$ confidence interval $[\mathrm{CI}], 3.14-23.71$ and OR, 15.83; 95\% CI, 4.62-54.22, respectively). Our findings suggest that children who had IR according to increased fixed or age-specific values of HOMA-IR were at greatest risk for MS compared with the UN group (OR, 8.63; 95\% CI, 3.17-23.45 and OR, 30.45; 95\% CI, 6.78-136.76, respectively). Among participants with IR, MS increased by 17.39-fold to 24.01fold in males according to FCOP or ACOP, respectively, but MS increased by 9.65 -fold only according to ACOP for fasting plasma insulin in females (Table 5). Obesity-related factors such as FM, percent body fat (PBF), trunk FM (\%), and FMI also had a significant association with MS (OR, 1.24; 95\% CI, 1.14-1.34, OR, 1.15; 95\% CI, 1.08-1.23, OR, 1.19; 95\% CI, 1.13-1.26 and OR, $1.75 ; 95 \%$ CI, $1.48-2.08$, respectively).

No difference was observed in fasting plasma insulin versus HOMA-IR for predicting MS. HOMA-IR is required as a

Table 3. Distribution of subjects by insulin resistance according to different cutoff points (FCOP, ACOP) of fasting plasma insulin or HOMAIR

\begin{tabular}{|c|c|c|c|c|c|c|c|c|}
\hline \multirow{2}{*}{ Variable } & \multicolumn{4}{|c|}{ Increased fasting plasma insulin } & \multicolumn{4}{|c|}{ Increased HOMA-IR } \\
\hline & Positive (FCOP) & Negative (FCOP) & Total & $P$-value & Positive (FCOP) & Negative (FCOP) & Total & $P$-value \\
\hline Positive (ACOP) & $101(43.7)$ & $0(0)$ & 101 & $<0.001$ & $102(37.5)$ & $0(0)$ & 102 & $<0.001$ \\
\hline Negative (ACOP) & $113(56.3)$ & $505(100)$ & 618 & & $151(62.5)$ & $466(100)$ & 617 & \\
\hline Total & 214 & 505 & 719 & & 253 & 466 & 719 & \\
\hline
\end{tabular}

Values are presented as number (\%).

FCOP, fixed cutoff points; ACOP, age-specific cutoff points; HOMA-IR, homeostasis model assessment for insulin resistance.

Table 4. A comparison of dyslipidemia in insulin resistance assessed using different cutoff points

\begin{tabular}{|c|c|c|c|c|c|c|}
\hline \multirow{2}{*}{ Variable } & \multicolumn{3}{|c|}{ Increased fasting plasma insulin } & \multicolumn{3}{|c|}{ Increased HOMA-IR } \\
\hline & $\operatorname{ACOP}(n=101)$ & FCOP $(n=214)$ & $P$-value & $\operatorname{ACOP}(n=101)$ & FCOP $(n=214)$ & $P$-value \\
\hline $\mathrm{TC}(\geq 200 \mathrm{mg} / \mathrm{dL})$ & $11(7.5)$ & $18(6.9)$ & 0.733 & $13(10.9)$ & $17(5.7)$ & $<0.001$ \\
\hline $\mathrm{TG}(\geq 130 \mathrm{mg} / \mathrm{dL})$ & $34(34.9)$ & $53(25.8)$ & 0.010 & $35(35.8)$ & $55(22.3)$ & 0.001 \\
\hline LDL-C ( $\geq 130$ mg/dL) & $7(7.0)$ & $14(5.9)$ & 0.571 & $7(6.6)$ & $13(4.8)$ & 0.345 \\
\hline $\mathrm{HDL}-\mathrm{C}\left(<40 \mathrm{mg} / \mathrm{dL}^{*}\right)$ & $29(31.8)$ & $52(26.8)$ & 0.156 & $28(27.2)$ & $61(26.7)$ & 0.901 \\
\hline
\end{tabular}

Values are presented as number (\%).

HOMA-IR, homeostasis model assessment for insulin resistance; ACOP, age-specific cutoff points; FCOP, fixed cutoff points; TC, total cholesterol; TG, triglyceride; LDL-C, low-density lipoprotein cholesterol; HDL-C, high-density lipoprotein cholesterol.

${ }^{*}<50$ for female whose age $\geq 16$.

Table 5. An analysis assessing the influence of insulin resistance on metabolic syndrome

\begin{tabular}{|c|c|c|c|c|c|c|}
\hline \multirow{2}{*}{ Variable } & \multicolumn{2}{|c|}{ Metabolic syndrome $(n=21)$} & \multicolumn{2}{|c|}{ Male $(n=12)$} & \multicolumn{2}{|c|}{ Female $(n=9)$} \\
\hline & OR (95\% Cl) & $P$-value & OR $(95 \% \mathrm{Cl})$ & $P$-value & OR $(95 \% \mathrm{Cl})$ & $P$-value \\
\hline \multicolumn{7}{|l|}{ Insulin } \\
\hline FCOP & $8.62(3.14-23.71)$ & $<0.001$ & 17.39 (3.70-81.80) & $<0.001$ & $2.89(0.65-12.78)$ & 0.160 \\
\hline ACOP & $15.83(4.62-54.22)$ & $<0.001$ & $24.01(5.14-112.11)$ & $<0.001$ & $9.65(1.56-59.57)$ & 0.015 \\
\hline \multicolumn{7}{|c|}{ HOMA-IR } \\
\hline FCOP & $8.63(3.17-23.45)$ & $<0.001$ & $16.11(3.52-73.69)$ & $<0.001$ & $3.19(0.73-14.01)$ & 0.124 \\
\hline ACOP & $30.45(6.78-136.76)$ & $<0.001$ & $19.70(4.22-91.84)$ & $<0.001$ & N/A & \\
\hline
\end{tabular}

OR, odds ratio; $\mathrm{Cl}$, confidence interval; FCOP, fixed cutoff points; ACOP, age-specific cutoff points; HOMA-IR, homeostasis model assessment for insulin resistance; N/A; not applicable. 
Table 6. Areas under the curves in the ROC according to each indicator of insulin resistance based on metabolic syndrome

\begin{tabular}{|c|c|c|c|c|}
\hline Variable & Sensitivity & Specificity & AUROC & $P$-value \\
\hline Total & & & & 0.386 \\
\hline FCOP & $0.359(0.358-0.361)$ & $0.943(0.943-0.944)$ & $0.764(0.676-0.851)$ & \\
\hline ACOP & $0.585(0.583-0.586)$ & $0.800(0.799-0.801)$ & $0.722(0.613-0.831)$ & \\
\hline Male & & & & 0.747 \\
\hline FCOP & $0.405(0.404-0.407)$ & $0.963(0.963-0.963)$ & $0.792(0.680-0.904)$ & \\
\hline ACOP & $0.625(0.624-0.627)$ & 0.849 (0.849-0.850) & $0.774(0.633-0.914)$ & \\
\hline Female & & & & 0.374 \\
\hline FCOP & $0.284(0.283-0.286)$ & $0.921(0.921-0.922)$ & $0.729(0.582-0.875)$ & \\
\hline ACOP & $0.518(0.516-0.520)$ & $0.746(0.745-0.746)$ & $0.654(0.481-0.827)$ & \\
\hline
\end{tabular}

calculation step; therefore, fasting plasma insulin can be used alone as an easy test to diagnose IR in adolescents, as reported previously. $^{2)}$

Table 6 depicts the sensitivity and specificity of each IR indicator for predicting MS. The AUCs for fasting plasma insulin were 0.767 (95\% CI, 0.676-0.851) using FCOP and 0.770 (95\% CI, 0.670-0.870) using ACOP. The AUCs for FCOP were 0.792 (95\% CI, 0.680-0.904) and 0.729 (95\% CI, 0.582-0.875) in males and females, respectively. The AUCs for ACOP were 0.774 (95\% CI, 0.633-0.914) in males and 0.654 (95\% CI, 0.481-0.827) in females. A comparison of the AUCs of each marker according to sex for MS showed no significant differences.

\section{Discussion}

In the present study, the mean values of FPG, TC, TG, low-density lipoprotein cholesterol, and HDL-C in the $\mathrm{OB}$ group were comparable to those of the UN group. Hypertriglyceridemia has been reported as the most frequently occurring form of dyslipidemia. ${ }^{5)}$ Li et al. ${ }^{24)}$ suggested that hypertriglyceridemia was significantly associated with the development of IR and MS. Several studies have reported varying prevalence rates of hypertriglyceridemia from different countries such as the United States (14.2\%), Iran (49.9\%), Turkey (21.7\%), and Germany (33.9\%). ${ }^{25-28)}$ Similarly, despite differences in ethnicity, the frequency of hypertriglyceridemia was 30.5\% in our study.

The prevalence of MS was $12.7 \%$ in the OB group aged from 10 to 17 years. For early detection of MS, we used values of abnormal $\mathrm{TG} \geq 130 \mathrm{mg} / \mathrm{dL}^{23)}$ and modified criteria concerning the MS definition. ${ }^{21)}$ Similarly, previous studies based on the IDF definition reported the prevalence of MS in children and adolescents ranged from $0.7 \%$ to $4.5 \%$ in population-based studies and from $0.2 \%$ to $27.6 \%$ according to weight status. ${ }^{6-9)}$ We found that the prevalence of MS was higher among males (7.2\%) than females (5.5\%) during adolescence. Some studies have shown a positive association between females and the presence of IR. ${ }^{29,30)}$ However, similar to other studies, we observed no significant difference in IR frequency in relation to sex. ${ }^{2,5)}$

The frequency of IR identified using fasting plasma insulin was almost the same as that of IR identified using HOMA-IR.
In our study, the prevalence of IR was between $35.9 \%$ and $63.7 \%$ in the OB group according to increased value of HOMA-IR or fasting plasma insulin (FCOP or ACOP). Similar observations have also been reported in previous studies. ${ }^{2,5,31)}$ In the United States, one study involving adolescents aged 12-19 years reported that the prevalence of IR in adolescents with obesity was $52.1 \%{ }^{32)}$ In another study of adolescents with obesity aged $12-15$ years, IR was found in $38 \%$ of participants. ${ }^{33)}$ Gobato et al. $^{34)}$ found that $29.1 \%$ of adolescents with obesity aged from 10-18 years were diagnosed with IR.

In our study, we found an association between FM, PBF, FMI, and IR and prevalence of MS. Moreover, accumulation of abdominal fat was associated with IR and MS. These findings were similar to those of previous reports. ${ }^{35,36)}$ Among participants with IR, MS increased by 17.39-fold to 24.01fold in males according to FCOP or ACOP, respectively. In females with IR according to ACOP of fasting plasma insulin, MS increased by 9.65 -fold. However, according to FCOP, no association was found between MS and IR. This suggests that IR using ACOP was more closely associated with MS than IR using FCOP. Statistically, this may be due to the low prevalence of MS (2.9\%) in the present study. Nevertheless, as shown in Table 6, both ACOP and FCOP were robust tools for the assessment of MS. IR using ACOP had a slightly lower specificity but higher sensitivity for MS than using FCOP. However, the AUCs for fasting plasma insulin using ACOP were not significantly different from those using FCOP. A comparison of the AUCs of each marker for MS according to sex did not show any significant difference. The prevalence of MS in participants with IR defined using ACOP and FCOP was similar. Overall, the results suggest that FCOP is a convenient indicator for clinical application, but there is a limit to IR risk assessment.

Hyperinsulinemia, rather than impaired fasting glucose, may play the largest causal role in the pathology and progression of metabolic derangement. Impaired fasting glucose is a late indicator of metabolic dysregulation. ${ }^{37)}$ HOMA-IR was not different from fasting plasma insulin in predicting MS in the present study. Fasting plasma insulin might be a simple, economic, and easier method to predict MS, although HOMAIR is required as a calculation step. Therefore, fasting plasma insulin may provide a simple marker for screening MS in 
children and adolescents.

In adults, Lunger et al. ${ }^{38)}$ evaluated methods for identifying IR in women with PCOS. The researchers set cutoff points for fasting insulin at $<7 \mu \mathrm{U} / \mathrm{mL}$. Ghasemi et al. ${ }^{39)}$ explored the relationship between early markers of IR with T2DM. The researchers elaborated on these findings through identifying optimal cutoff points ( $75 \%$ sensitivity) for fasting insulin at 7.51 $\mu \mathrm{U} / \mathrm{mL}$ in women and $5.48 \mu \mathrm{U} / \mathrm{mL}$ in men. The fasting plasma insulin cutoff limit for IR in adolescents was found at a relatively higher level than in adults in the present study, and this may be related to puberty. A previous study demonstrated that IR could occur during puberty in relation to age and changes in body composition. ${ }^{2)}$ IR is more closely related to age than pubertal stage; therefore, it is possible to propose specific fasting plasma insulin and HOMA-IR values for each age group and sex. ${ }^{2,15,16)}$

In this large retrospective study, different measures of IR were used in analysis. However, our study had some limitations. One limitation was the small number of participants with MS and a lack of comparison with the gold standard methods for IR. Moreover, the present study involved a population of Korean healthy adolescents; therefore, these results may not be readily generalizable elsewhere.

In conclusion, the prevalence of MS in participants with IR defined using ACOP was similar to those found using FCOP. However, IR using ACOP was more closely associated with MS than IR using FCOP. To determine the clinical application of fasting plasma insulin and HOMA-IR values together with age, further longitudinal risk association studies are required.

\section{Ethical statement}

All participants in KNHANES $V$ provided informed consent. The protocol for KNHANES V was approved by the Institutional Review Board (IRB) of the Korea Centers for Disease Control and Prevention. Our study was approved by the IRB of the Catholic University of Korea (IRB No. KC19ZASE0821).

\section{Conflict of interest}

No potential conflict of interest relevant to this article was reported.

\section{Acknowledgments}

Statistical consultation was supported by a grant from the Korean Health Technology R\&D Project, Ministry of Health \& Welfare, Republic of Korea (grant number: HI14C1062).

\section{References}

1. Lim SS, Vos T, Flaxman AD, Danaei G, Shibuya K, AdairRohani H, et al. A comparative risk assessment of burden of disease and injury attributable to 67 risk factors and risk factor clusters in 21 regions, 1990-2010: a systematic analysis for the Global Burden of Disease Study 2010. Lancet 2012;380:2224-60.

2. Nogueira-de-Almeida CA, de Mello ED. Different criteria for the definition of insulin resistance and its relation with dyslipidemia in overweight and obese children and adolescents. Pediatr Gastroenterol Hepatol Nutr 2018;21:59-67.

3. de Onis M. Preventing childhood overweight and obesity. J Pediatr (Rio J) 2015;91:105-7.

4. Kurtoglu S, Hatipoglu N, Mazicioglu M, Kendirici M, Keskin M, Kondolot M. Insulin resistance in obese children and adolescents: HOMA-IR cut-off levels in the prepubertal and pubertal periods. J Clin Res Pediatr Endocrinol 2010;2:100-6.

5. Yi KH, Hwang JS, Kim EY, Lee SH, Kim DH, Lim JS. Prevalence of insulin resistance and cardiometabolic risk in Korean children and adolescents: a population-based study. Diabetes Res Clin Pract 2014;103:106-13.

6. Papoutsakis C, Yannakoulia M, Ntalla I, Dedoussis GV. Metabolic syndrome in a Mediterranean pediatric cohort: prevalence using International Diabetes Federationderived criteria and associations with adiponectin and leptin. Metabolism 2012;61:140-5.

7. Ford ES, Li C, Zhao G, Pearson WS, Mokdad AH. Prevalence of the metabolic syndrome among U.S. adolescents using the definition from the International Diabetes Federation. Diabetes Care 2008;31:587-9.

8. Schwandt P, Kelishadi R, Haas GM. Ethnic disparities of the metabolic syndrome in population-based samples of german and Iranian adolescents. Metab Syndr Relat Disord 2010;8:189-92.

9. Chen F, Wang Y, Shan X, Cheng H, Hou D, Zhao X, et al. Association between childhood obesity and metabolic syndrome: evidence from a large sample of Chinese children and adolescents. PLoS One 2012;7:e47380.

10. Levy-Marchal C, Arslanian S, Cutfield W, Sinaiko A, Druet C, Marcovecchio ML, et al. Insulin resistance in children: consensus, perspective, and future directions. J Clin Endocrinol Metab 2010;95:5189-98.

11. Tam CS, Xie W, Johnson WD, Cefalu WT, Redman LM, Ravussin E. Defining insulin resistance from hyperinsulinemic-euglycemic clamps. Diabetes Care 2012;35:1605-10.

12. Keskin M, Kurtoglu S, Kendirci M, Atabek ME, Yazici C. Homeostasis model assessment is more reliable than the fasting glucose/insulin ratio and quantitative insulin sensitivity check index for assessing insulin resistance among obese children and adolescents. Pediatrics 2005;115:e500-3.

13. Weiss R, Dziura J, Burgert TS, Tamborlane WV, Taksali SE, Yeckel CW, et al. Obesity and the metabolic syndrome in children and adolescents. N Engl J Med 2004;350:2362-74.

14. Mieldazis SF, Azzalis LA, Junqueira VB, Souza FI, Sarni RO, 
Fonseca FL. Hyperinsulinism assessment in a sample of prepubescent children. J Pediatr (Rio J) 2010;86:245-9.

15. Almeida CA, Pinho AP, Ricco RG, Pepato MT, Brunetti IL. Determination of glycemia and insulinemia and the homeostasis model assessment (HOMA) in schoolchildren and adolescents with normal body mass index. J Pediatr (Rio J) 2008;84:136-40.

16. Garcia Cuartero B, Garcia Lacalle C, Jimenez Lobo C, Gonzalez Vergaz A, Calvo Rey C, Alcazar Villar MJ, et al. The HOMA and QUICKI indexes, and insulin and C-peptide levels in healthy children. Cut off points to identify metabolic syndrome in healthy children. An Pediatr (Barc) 2007;66:481-90.

17. Matthews DR, Hosker JP, Rudenski AS, Naylor BA, Treacher DF, Turner RC. Homeostasis model assessment: insulin resistance and beta-cell function from fasting plasma glucose and insulin concentrations in man. Diabetologia 1985;28:412-9.

18. Stevens GA, Singh GM, Lu Y, Danaei G, Lin JK, Finucane MM, et al. National, regional, and global trends in adult overweight and obesity prevalences. Popul Health Metr 2012;10:22.

19. Ten S, Maclaren N. Insulin resistance syndrome in children. J Clin Endocrinol Metab 2004;89:2526-39.

20. Kim JH, Yun S, Hwang SS, Shim JO, Chae HW, Lee YJ, et al. The 2017 Korean National Growth Charts for children and adolescents: development, improvement, and prospects. Korean J Pediatr 2018;61:135-49.

21. Zimmet P, Alberti KG, Kaufman F, Tajima N, Silink M, Arslanian S, et al. The metabolic syndrome in children and adolescents - an IDF consensus report. Pediatr Diabetes 2007;8:299-306.

22. Expert panel on integrated guidelines for cardiovascular health and risk reduction in children and adolescents: summary report. Pediatrics 2011;128 Suppl 5:S213-56.

23. Highlights of the report of the expert panel on blood cholesterol levels in children and adolescents. National Cholesterol Education Program Expert Panel on Blood Cholesterol Levels in Children and Adolescents. Am Fam Physician 1992;45:2127-36.

24. Li Z, Deng M, Tseng C-H, Heber D. Hypertriglyceridemia is a practical biomarker of metabolic syndrome in individuals with abdominal obesity. Metab Syndr Relat Disord 2013;11:87-91.

25. Li J, Motsko SP, Goehring EL Jr, Tave A, Pezzullo JC, Jones JK. Prevalence of pediatric dyslipidemia: comparison of a population-based claims database to national surveys. Pharmacoepidemiol Drug Saf 2010;19:1031-40.

26. Hashemipour M, Soghrati M, Malek Ahmadi M, Soghrati M. Anthropometric indices associated with dyslipidemia in obese children and adolescents: a retrospective study in isfahan. ARYA Atheroscler 2011;7:31-9.
27. Elmaoğulları S, Tepe D, Uçaktürk SA, Karaca Kara F, Demirel F. Prevalence of dyslipidemia and associated factors in obese children and adolescents. J Clin Res Pediatr Endocrinol 2015;7:228-34.

28. Korsten-Reck U, Kromeyer-Hauschild K, Korsten K, Baumstark MW, Dickhuth H-H, Berg A. Frequency of secondary dyslipidemia in obese children. Vascular Health Risk Managem 2008;4:1089-94.

29. Madeira IR, Bordallo MA, Carvalho CN, Gazolla FM, de Souza FM, de Matos HJ, et al. The role of metabolic syndrome components and adipokines in insulin resistance in prepubertal children. J Pediatr Endocrinol Metab 2011;24:289-95.

30. Tester J, Sharma S, Jasik CB, Mietus-Snyder M, TinajeroDeck L. Gender differences in prediabetes and insulin resistance among 1356 obese children in Northern California. Diabetes Metab Syndr 2013;7:161-5.

31. Juarez-Lopez C, Klunder-Klunder M, Medina-Bravo P, Madrigal-Azcarate A, Mass-Diaz E, Flores-Huerta S. Insulin resistance and its association with the components of the metabolic syndrome among obese children and adolescents. BMC Public Health 2010;10:318.

32. Lee JM, Okumura MJ, Davis MM, Herman WH, Gurney JG. Prevalence and determinants of insulin resistance among U.S. adolescents: a population-based study. Diabetes Care 2006;29:2427-32

33. Pulungan AB, Puspitadewi A, Sekartini R. Prevalence of insulin resistance in obese adolescents. Paediatr Indones 2013;53:167-72.

34. Gobato AO, Vasques AC, Zambon MP, Barros Filho Ade A, Hessel G. Metabolic syndrome and insulin resistance in obese adolescents. Rev Paul Pediatr 2014;32:55-62.

35. Kim K, Park SM. Association of muscle mass and fat mass with insulin resistance and the prevalence of metabolic syndrome in Korean adults: a cross-sectional study. Sci Rep 2018;8:2703

36. Trirogoff ML, Shintani A, Himmelfarb J, Ikizler TA. Body mass index and fat mass are the primary correlates of insulin resistance in nondiabetic stage 3-4 chronic kidney disease patients. Am J Clin Nutr 2007;86:1642-8.

37. Fung J, Berger A. Hyperinsulinemia and insulin resistance: scope of the problem. J Insulin Resist 2016;1:1-6.

38. Lunger F, Wildt L, Seeber B. Accurate screening for insulin resistance in PCOS women using fasting insulin concentrations. Gynecol Endocrinol 2013;29:541-4.

39. Ghasemi A, Tohidi M, Derakhshan A, Hasheminia M, Azizi F, Hadaegh F. Cut-off points of homeostasis model assessment of insulin resistance, beta-cell function, and fasting serum insulin to identify future type 2 diabetes: Tehran Lipid and Glucose Study. Acta Diabetol 2015;52:905-15. 